\title{
Connecting self-efficacy and nature of science shifts in undergraduate research experiences
}

\author{
Gina Quan and Andrew Elby \\ University of Maryland, College Park \\ 082 Regents Drive, College Park, Maryland, 20742
}

\begin{abstract}
Undergraduate research can support students' more central participation in physics. We present analysis of one way this participation may shift: changes in their beliefs about the Nature of Science coupled to changes in a sense of ability to contribute to authentic research. Students in the study worked with faculty and graduate student research mentors on research projects and also participated in a seminar where they learned about research and reflected on their experiences. In videotaped interviews, we asked students to describe their experiences in research. Students developed nuanced views about how the research process works coupled to shifts in their sense of confidence in ability to contribute to research, feeling like their contributions as novices mattered.
\end{abstract}

PACS: 01.40.-d, 01.40.Fk, 01.30.Cc

\section{INTRODUCTION}

Research suggests that participating in undergraduate research is beneficial for many reasons. Undergraduate research impacts students' identity alignment with science, self-efficacy about doing research, understanding of how research works, and development of technical skills and content knowledge [1-3]. Participation in undergraduate research also influences students' career choice, clarifying interest in pursuing graduate studies [1-2]. These results are consistent across different research methods, including student surveys [2-3] and ethnographic investigations [5,7].

However, participating in undergraduate research is not equally productive for all students. The extent to which research is beneficial is impacted by the type of research program, day-to-day work, and mentorship quality [2,4-6]. These results motivate research that goes beyond documenting which aspects of a research experience lead to positive shifts in attitudes and understanding; we need to understand how these shifts come about and how they impact students' larger trajectory in research. In particular, understanding how shifts along one dimension trigger or support a shift in another can help uncover mechanisms by which research may be productive, and could be made more productive. Our exploratory foray into this landscape zooms in on one connection; shifts in students' views about the Nature of Science coupling to self-efficacy in doing research.

This coupling is worth studying partly because the two connected constructs are consequential in their own right: Self-efficacy, or belief in one's physics ability, is tied to student success in physics [8]. Though self-efficacy often refers to belief in ability to complete a specific task, what emerged in our data was broader sense of confidence; students developed beliefs that they could make meaningful contributions to authentic research. For the purposes of this paper, we label student statements related to confidence and ability in research as "self-efficacy," while acknowledging that we are using this term more broadly than some.

Many science educators consider sophisticated views on the Nature of Science to be an instructional goal. Nature of Science views span many dimensions, but we focus on shifts in science as a social enterprise; that science involves many people with a diversity of skills [9]. We highlight the way shifts in self-efficacy and in views about the Nature of Science as a social enterprise may interact, motivating future work on this particular connection and on links between other potential outcomes of undergraduate research experiences.

\section{CLASSROOM CONTEXT}

Physics 299B: The Physics Student in the University was developed in Spring 2013 at the University of Maryland, College Park. The first author co-developed and co-taught the course in 2013 and 2014. 299B introduces undergraduate freshmen and first-year transfer students to authentic physics research. All first-year physics majors who were not currently engaged in research were encouraged to enroll during advising. Instructors recruited mentors (faculty, post-docs, and advanced graduate students) and mentors proposed projects that were of reasonable complexity for a first-year undergraduate to complete in one semester. Students were matched with mentors based on project interest. For 3-5 hours per week for 15 weeks, students worked with their mentors on research projects. In addition, students met for two hours per week in the 299B seminar. This course covered research skills such as reading literature and keeping a lab notebook. It also emphasized community-building and supporting one another through the difficulties of research. 


\section{METHODS}

In Spring 2014, we videotaped the 299B sessions and collected instructor field notes and student coursework. In Summer and Fall 2014, we invited all fifteen students be interviewed, and collected nine interviews. The semistructured interviews (full protocol at ter.ps/int299b) probed students' attitudes toward research before and after the research experience, as well as what they felt like they got out of doing research.

In analyzing transcriptions of a few interviews, we noticed a connection between students' Nature of Science and self-efficacy shifts. To test this idea, we conducted a progressive refinement of hypothesis, iteratively developing research claims, writing analytical memos, testing the claim against a larger set of data, and then refining the research claim [10]. In addition, we presented video data and our analyses to our full research group, to identify and discuss multiple interpretations and identify the interpretation best supported by data. We repeated this process in analyzing interviews with the other students in this data set.

Based on these analyses, seven of the nine students interviewed in 2014 described self-efficacy shifts connected to Nature of Science shifts. However, the finer grained details of these shifts varied. In this paper, we focus on two students whose experiences illustrate both the variations in the details and also the commonalities among the shifts. Wyatt found that cosmology research didn't require advanced mathematics, and that there was a place for novices to participate. This contributed to his shift toward thinking he could make worthwhile research contributions. By contrast, Frederick came to see lack of certainty- a sense that "nobody knows what they're doing" —as part of the research process. His sense that uncertainty was a normal part of research, we argue, contributed to his increased sense that he could contribute to research. Although the evidence is tentative, we argue in both of these cases that these shifts in Nature of Science views and in self efficacy are coupled rather than merely contemporaneous.

\section{WYATT}

\section{A. Shifts in Wyatt's Nature of Science views}

Wyatt's Nature of Science views shift along the science as a social enterprise dimension. He describes research as a hierarchy with room for novices (such as himself) at multiple points in the interview. We present two excerpts and quote other interview data in this analysis.

Wyatt: You're always kinda intimidated at first when you get into research. Cause you're like, postdocs and you don't wanna waste their time, and they work on big things and it's like oh, I'm just a freshman.

Interviewer: So do you feel like you're less intimidated by your research now?

Wyatt: Ah yeah definitely. Cause I don't know, there's always a place for anyone with a certain, skill level... the experts are always gonna be at the top. And wherever they need you, if they decide to choose you at all, that's probably where you're gonna have the best fit.

Interviewer: Mm, So do you feel like you've like, moved up in your fit?

Wyatt: Yeah, a little bit actually. I mean, not just being a sophomore in college as opposed to a freshman, but like having the experience and getting things done, presenting things... I feel a little bit more proficient in research.

Wyatt describes initially having a sense that research is hierarchical, with those at the "top" having knowledge and experience. He compares his status as "just a freshman” to post-docs, suggesting that experience and coursework is necessary to doing research. In his description, his overall view of science as hierarchical did not change. What changed was his sense that there is room at the bottom for novices to make meaningful contributions: "There's always a place for anyone with a certain skill level.” This hierarchy also supports upward movement; Wyatt has a sense that he's already moved to higher position, having gained more experience in research and in college.

Contributing to Wyatt's swing toward thinking that "there's always a place" even for novices is a shift in his views about the nature of cosmology research in particular. He describes his first impression of cosmology research as "a mess of math that I am nowhere near prepared for." However, he found that it involved more concrete activities such as "churning data" and "computing data":

Wyatt: [At first] I was like, man that's serious cosmology. That's probably a mess of math that I am nowhere near prepared for. But I like astronomy so much so, I was like "man let me just go for it.” And then what I realized it's not so much like, raw theory. They actually do have telescopes, hardware that take all these measurements, and you're just computing all that data... I imagined cosmology being a whole lot more theory... We churn out that data to have something readable, something understandable. And that actually surprised me and changed my view of cosmology.

Wyatt found that some aspects of cosmology research are less math-intensive and theoretical than he thought, which (we now argue) is connected to a sense that he can understand and participate in it.

\section{B. Shifts in Wyatt's self-efficacy}

We see that Wyatt also gains confidence that he's able to contribute to authentic research. His first impression was that research is "intimidating." He positioned himself below 
his mentors, "they work on big things... I'm just a freshman," giving a sense that he feels small compared them. Through participating in research, he sees a place for novices like him to make authentic contributions. By the end of the research experience, Wyatt describes himself as "more proficient in research," and has moved up in his fit, suggesting an increased sense of competence.

Wyatt's intimidation in part stemmed from his sense of his math skills, and he worried about being prepared mathwise. He described the lack of mathematics as important for his participation in the project: "It was less computational than I thought it would be which was a godsend, because my math isn't the strongest.” In this statement, he suggests that his math ability would hold him back. Wyatt gained confidence in being able to understand his project. He describes the project as "concrete... we churn out that data to have something readable, something understandable," suggesting that it is understandable to himself. His use of "we" places himself in an active role in the project.

\section{Self-efficacy and Nature of Science connection}

Wyatt's shift in sense of science as a social enterprise to which novices can contribute is connected to his sense that he can contribute to authentic research. As he learns that there's "a place for anyone with a certain skill level," his "freshman" status is less of a barrier to participation. The hierarchical nature of his relationship to his mentors also was a source of confidence: "they'll tell you how to correct it. ...you still have the reassurance, if this is wrong, they'll probably spot it.” This statement reflects Wyatt's sense of reassurance and protection in his mentors' expertise.

Wyatt's initial sense that his research would be mathintensive is tied to a lack of confidence going in. He describes his math ability as low, and his initial view of cosmology as being theoretical made him feel unprepared. That his research in cosmology was data-driven and not mathematically challenging also meant that his math ability was much less of a concern.

\section{FREDERICK}

Now we turn to a student who experienced self-efficacy and Nature of Science shifts differently from Wyatt, but whose shifts are nonetheless coupled. We use data from a class discussion at the end of the semester where Frederick describes coming to see scientific research as more uncertain and becomes less nervous about his lack of understanding.

\section{A. Shifts in Frederick's self-efficacy}

Frederick describes gaining confidence in his ability to “adapt” to a new research situation:

I'd say that no matter what research opportunity I walked into at this point, I wouldn't be nervous. You know that first time you walk into a research opportunity, you're kinda nervous, you don't know how it's gonna be, you don't know how everything's gonna go down. And I feel like after this experience, I could walk into any research opportunity and, adapt... I feel like I could walk in there with no nervousness now and own it.

He initially describes nervousness upon starting one's first research experience, which for him stemmed from not knowing what was going to happen. In contrast, he says he is now able to start a new project with confidence. His sense of his trajectory in research goes from nervousness, to adapting, to confidence and owning it.

\section{B. Shifts in Frederick's Nature of Science views}

In the same discussion, instructors asked students what they felt like they learned about the process of doing science. Frederick said,

Nobody knows what they're doing. Seriously. How many people were like oh, I know exactly where I'm trying to get to and we're gonna figure this out? Everybody's just kinda ad-libbing it with a general idea of where they want to go. If they get there awesome, if they get somewhere else that's awesome too. Hopefully you just get somewhere away from your starting point.

Though Frederick says "nobody knows what they're doing," his statement is more nuanced than suggesting that researchers are totally lost. He highlights how in science, the outcome is often uncertain and that having flexibility is productive. This contrasts with a common perception that researchers know "exactly where I'm trying to get to." Frederick's statement also reflects a sense that experts don't have all the answers, and expresses the value of unexpected results.

\section{Self-efficacy and Nature of Science connection}

In this section, we describe a plausible connection between Frederick's growth in self-efficacy and shifts in his Nature of Science views. After some discussion, he elaborated on not feeling nervous anymore, and suggests that not knowing what one is doing is okay in research.

I should probably elaborate. What I meant, it's a process. Nervous about the process. I walked into something where I had no idea what I was doing, Logan [my partner] had no idea what he was doing, [my mentor] had no idea what he was doing. That was our mentor and he was like, I don't know where this is gonna go. ...The process of learning and understanding our topic so quickly gave me a lot of confidence that I could walk 
into any of them, and pick it up like that, the process would be a lot simpler, I wouldn't be nervous about it.

One explicitly-stated source of Frederick's self-efficacy is the process of picking up his research quickly. We suggest that in addition to this, his sense that experts "didn't know what they were doing” reduced his own nervousness about not knowing what he himself was doing. Frederick emphasizes how neither he, his partner, nor his mentor knew what they were doing. He discursively groups the three of them together, suggesting that they are on the same level. Before and after this phrase, he describes nervousness and confidence, which suggests a connection between developing his confidence and a sense that researchers don't know exactly what's going to happen.

\section{DISCUSSION}

Previous research on undergraduate research experiences has documented self-efficacy and Nature of Science gains. In this paper, we gave evidence that these constructs can interact: Wyatt, Frederick, and other students not discussed in this paper developed a sense of science as something that novices can contribute to, connected to a shift in their sense of perceived ability to make a meaningful contribution. Wyatt and Frederick illustrate how a diversity Nature of Science and self-efficacy shifts can fit into this general pattern. To be clear, our purpose in this paper is not to generalize this connection; large-N studies are needed to confirm or disconfirm generalizability. Our purpose is to illustrate what such a coupling might look like to call attention to the phenomenon and to inform the design of large-N studies.

Our own future work will explore how the details of these shifts depend on the many contexts in which students engage in research, as well as the stability of these shifts over time. The term "research experience" is broad, and we expect that what students learn about science- and how this couples to self-efficacy - varies across projects. For instance, another student with the same concerns about math as Wyatt might instead have opportunities to use and feel competent in math rather than learn that valuable research can be done without mathematical expertise.

[1] E. Seymour et. al., Science Education 88, 4 (2004).

[2] R. Taraban and E. Logue, Journal of Ed. Psych. 104, 2 (2012).

[3] D. Lopatto, Cell Biology Education 3, 4 (2004).

[4] S. E. Branch, A. Woodcock, and W.G. Graziano, Journal of Engineering Education 104, 2 (2015).

[5] S. L. Laursen et. al., Undergraduate research in the sciences (John Wiley and Sons, San Francisco, 2010).

[6] D. Lopatto and S. Tobias, Council on Undergraduate Research (2010).
Though Wyatt eventually found cosmology understandable, his math confidence didn't shift. A different student might not see her lab-based activity as authentic science (as was the case for one student) and as a result, not gain a sense of competence in doing research.

Future work will also identify consequential aspects of the classroom context that students experienced along with their research. The 299B course explicitly discussed students' emotional experiences with respect to research. Weekly in-class reflections likely influenced students' interpretation and re-interpretation of their experiences and influenced their willingness to share during class (and interviews). More work is needed to see whether a similar Nature of Science and self-efficacy connection exists in research programs with different goals and support structures.

Finally, many students in the study described initial feelings of intimidation. For example, many students described feeling like first-years don't have enough background knowledge to do research. Others thought that they weren't talented enough relative to their peers. Our research (i) points to the importance of lowering barriers to participation and supporting students as they begin research and (ii) suggests that helping them shift their views about the Nature of Science as a social enterprise could potentially lower those barriers.

Of course, the first step is getting students to try research in the first place. Some 299B students said they would not have pursued research without this course. Like a third of 299B students, Wyatt and Frederick continued to work with their research mentors through summer, which we take as evidence of their success. Typical university patterns of students self-selecting into research, and finding research by word of mouth, risks losing students who have the potential to become great researchers.

\section{ACKNOWLEDGEMENTS}

The authors gratefully thank Dimitri Dounas-Frazer, Angela Little and the UMD Physics Education Research Group. This work is supported by NSF DUE- 1245590 and the University of Maryland Physics Department.

[7] A. B. Hunter, S. L. Laursen, and E. Seymour, Sci. Ed. 91, 1 (2007).

[8] V. Sawtelle, E. Brewe, and L. H. Kramer, Journal of research in science teaching 49, 9 (2012).

[9] N. G. Lederman, Journal of research in science teaching 29, 4 (1992).

[10] R. A. Engle, F. R. Conant, and J. G. Greeno, in Video research in the learning sciences, edited by $\mathrm{R}$. Pea, B.

Barron and S. J. Derry. (Routledge, NY 2007). 